\title{
Semantic and phonological knowledge of native signers of American Sign Language (ASL) in a synonym task
}

\author{
Rama Novogrodsky, Sarah Fish and Robert Hoffmeister. \\ Center for the Study of Communication and the Deaf, Boston University.
}

Research investigating word recognition and word recall in hearing children has historically shown errors shifting from being primarily phonological to primarily semantic as children increase in age. Such findings exist for written word recognition (Bach \& Underwood, 1970) and for spoken word recognition (Felzen \& Anisfeld, 1970). Young children, at the beginning of elementary school, are more likely to falsely choose words that rhymed with the prompt items, when choosing the incorrect response. In contrast, older children (11-year-olds) are more likely to falsely choose words that are semantically related to the prompt items.

The current study tested whether this phenomenon also holds true for native signers (Deaf children of Deaf parents) of American Sign Language (ASL). We explored the correct performance on an ASL synonyms task and the patterns of errors that appeared, as they can provide insight into what strategies children use when they do not know the right answer.

\section{Method}

250 native signers aged 4;0-18;0 were tested. They were divided to younger age group at elementary school $(4 ; 0-11 ; 0)$ and older age group at middle and high school $(12 ; 0-18 ; 0)$. The task was a receptive 15-question multiple choice test of ASL synonyms (Hoffmeister, Greenwald, Bahan \& Cole, 1989). Each question of the test consists of a prompt (1), the target (a), and three out of four additional possible response options: a semantic foil (b), a close phonological foil to the prompt (c), a distant phonological foil to the prompt (d) and an unrelated foil (e). Phonological distance was determined by the number of feature differences between the two signs.

(1) Prompt: shock
a. Target: legs-up
b. Semantic foil to the prompt and the target: leg-wobble
c. Close phonological foil to the prompt: rain
d. Distant phonological foil to the prompt: curly
e. Unrelated foil: $g o$

Error analysis: Based on MacSweeney, Capek, Campbell \& Woll (2009), Mayberry \& Fischer (1989) and Mayberry, Hatrak \& Morgan (2011), we predicted that, as they increase in age, native signers will prefer semantic foils over phonological foils, and when phonological foils are chosen, close phonological foils will be preferred over distant phonological foils. Thus, the hypothesized ranking order of response option preference was the following: The correct response was ranked the highest, followed by the semantic foil. The close phonological foil was predicted to be next, followed by distant phonological foil, with the unrelated foil predicted to be the least-preferred. 


\section{Results}

The older group had a much higher overall average score on the ASL synonyms task than the younger group $\left(85 \% ; 61 \%\right.$, respectively) ${ }^{1}$, outperforming the younger group on each of the 15 questions (Figure 1). As can be seen in Table 1, errors' analysis revealed that in the older age group when children did not choose the correct response they preferred the semantic foil over the close phonological foil and the close phonological foil over the distant phonological foil. The unrelated foil was the least-preferred. In The older age group for 10/15 questions, SpearmanRank-Order-Correlation was equal to 1 . In the younger age group this pattern was found only for $7 / 15$ questions. Spearman-Rank-Order-Correlation of the average of the questions showed significant higher correlation of the older group $\left(\mathrm{r}_{\mathrm{s}}=0.93\right)$ compared with the younger group $\left(\mathrm{r}_{\mathrm{s}}=\right.$ $0.83),(\mathrm{t}(28)=1.76, p<.05)$. This result suggests that, as Deaf children increase in age, they tend to prefer semantic foils over phonological foils. In addition, when they need to choose between two phonological foils, they prefer the phonologically close foils over the phonologically distant foils.

\section{Conclusion}

The findings show that the ASL vocabulary development of native signers follows the typical developmental path exhibited by children natively acquiring spoken language vocabulary. Both higher correct performances of the older age group and the preference of semantic foils in this group reveals that with age Deaf children rely more on semantic knowledge in order to complete a synonyms task, which requires this type of knowledge. This pattern is similarly to findings in typically developing hearing children (Bach \& Underwood, 1970; Felzen \& Anisfeld, 1970). In addition, the preference of close phonological foils over distant phonological foils demonstrates an increasing awareness of the phonological structure of signs with age. This result contributes to the study of neighborhood phonological density from a developmental point of view. The term "neighbors" is used for words that differ from one another by a single phoneme addition, deletion, or substitution in any position (Garlock, Walley \& Metsala, 2001). In the current task the close phonological foils are examples of neighbors compared with the distant phonological foils, as the former differed in only one phonological feature from the prompt. The current results suggest that with age Deaf children tend to choose neighbor signs over signs that do not belong to the same category of neighborhood phonological density. Garlock, et al., (2001) suggest that effect of neighborhood density (facilitation and inhibition) on word recognition tasks interacts with age of acquisition effects and frequency effects. This question needs to be further study in the case of signed languages.

To conclude, the current study, presenting results from a manual modality, support the assumption that lexical candidates compete with one another during word recognition (Luce \& Pisoni, 1998; Norris, 1994, among others). The results suggest that during the acquisition of ASL there is a developmental shift from phonological to semantic association between words.

\footnotetext{
${ }^{1}$ For detailed developmental results see Novogrodsky, Fish, \& Hoffmeister (2014).
} 


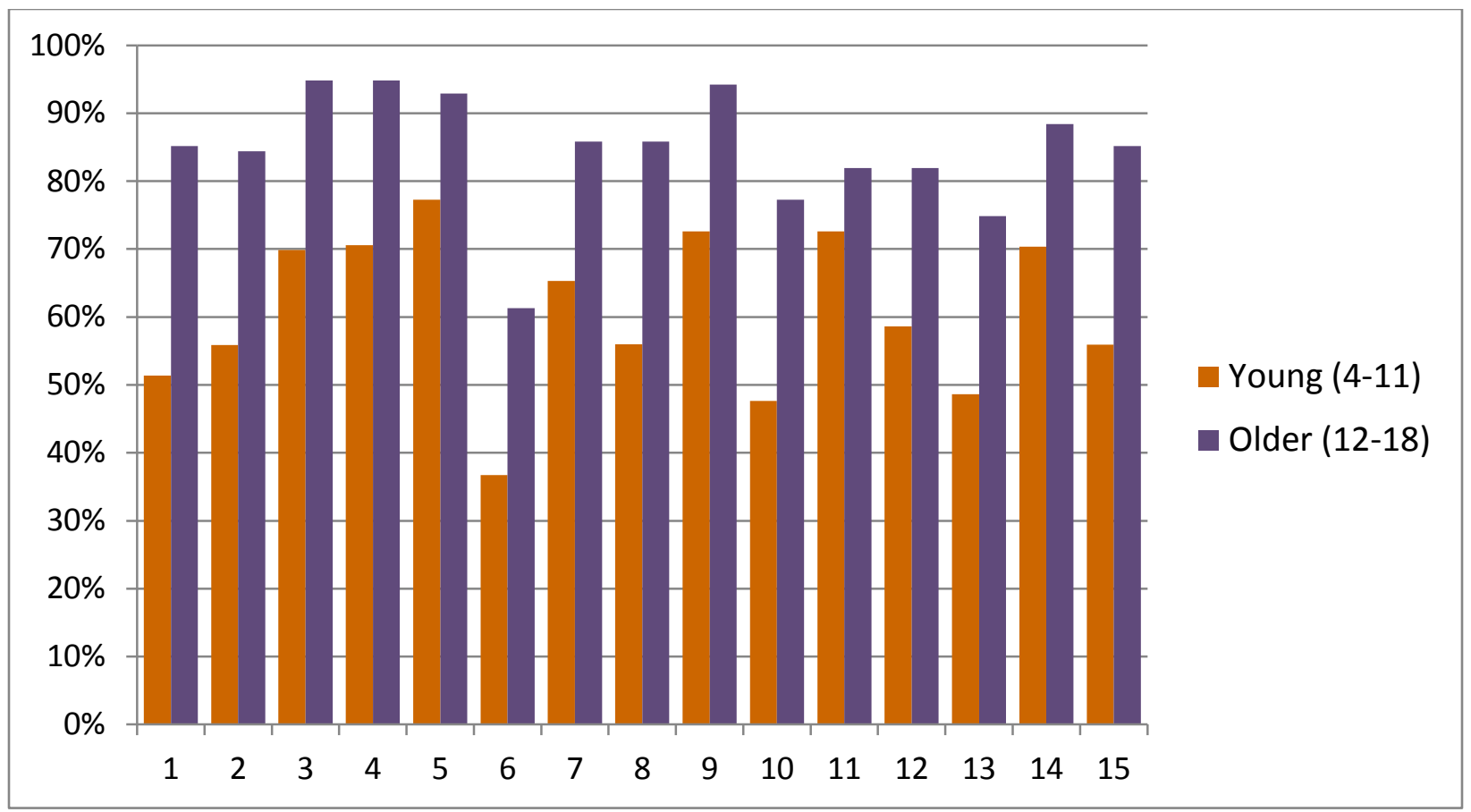

Figure 1. Correct performance as a function of question and age group.

Table 1. Spearman-Rank-Order-Correlation per question and group

\begin{tabular}{cccccccccccccccc}
\hline & $\begin{array}{c}\text { Questions demonstrating semantic foils } \\
\text { versus phonological foils }\end{array}$ & \multicolumn{3}{c}{$\begin{array}{c}\text { Questions demonstrating } \\
\text { close versus distant } \\
\text { phonological foils }\end{array}$} & \multicolumn{3}{c}{$\begin{array}{c}\text { Other } \\
\text { combinations of } \\
\text { foils }\end{array}$} \\
\hline Question & 1 & 6 & 7 & 9 & 10 & 12 & 15 & 2 & 3 & 4 & 5 & 13 & 8 & 11 & 14 \\
\hline Younger & 0.6 & 0.4 & 0.8 & 1 & 1 & 1 & 1 & 1 & 1 & 0.6 & 0.8 & 0.8 & 0.8 & 0.8 & 1 \\
Older & 0.8 & 0.8 & 1 & 1 & 1 & 1 & 1 & 1 & 1 & 1 & 0.8 & 0.8 & 1 & 0.8 & 1 \\
\hline
\end{tabular}




\section{References}

Bach, M.J. \& Underwood, B.J. (1970). Developmental changes in memory attributes. Journal of Educational Psychology, 61, 292-296.

Dewhurst, S. A., \& Robinson, C. A. (2004). False Memories in Children Evidence for a Shift from Phonological to Semantic Associations. Psychological Science, 15(11), 782-786.

Felzen, E. \& Anisfeld, M. (1970). Semantic and phonetic relations in the false recognition of words by third- and sixth-grade children. Developmental Psychology, 3, 163-168.

Garlock, V. M., Walley, A. C., \& Metsala, J. L. (2001). Age-of-acquisition, word frequency, and neighborhood density effects on spoken word recognition by children and adults. Journal of Memory and language, 45(3), 468-492.

Hoffmeister, R., Greenwald, J., Bahan, B., \& Cole, J. 1989. The American Sign Language Assessment Instrument. Unpub instrument: Boston University Center for the Study of Communication and the Deaf.

Luce, P. A., \& Pisoni, D. B. (1998). Recognizing spoken words: The Neighborhood Activation Model. Ear \& Hearing, 19, 1-36.

MacSweeney, M., Capek, C., Campbell, R., \& Woll, B. (2009). The signing brain: The neurobiology of sign language. Trends in Cognitive Sciences, 12, 232-240.

Mayberry, I. R. \& Fischer D.S. (1989). Looking through phonological shape to lexical meaning: The bottleneck of non-native sign language processing. Memory \& Cognition, 17, 740754.

Mayberry, R., Hatrak, M., \& Morgan, H. (2011). Age of acquisition affects the learning of phonological structure in ASL. Presented at the Boston University Conference on Language Development, 36, Boston, MA.

Norris, D. (1994). Shortlist: A connectionist model of continuous speech recognition. Cognition, $52,189-234$.

Novogrodsky, R., Fish, S., \& Hoffmeister, R. (2014). The acquisition of synonyms in American Sign Language (ASL): Towards a further understanding of the components of ASL vocabulary knowledge. Sign Language Studies, 14 (2). 